\title{
Experimental Comparison between Two Types of Hybrid Composite Materials in Compression Test
}

\author{
Suhad D. Salman ${ }^{1,2, *}$, W.S. Wan Hassim ${ }^{1}$, Z. Leman ${ }^{1}$ \\ ${ }^{1}$ Department of Mechanical and Manufacturing Engineering, Faculty of Engineering, Universiti Putra Malaysia, Malaysia \\ ${ }^{2}$ Department of Materials Engineering, Faculty of Engineering, The University of Mustansiriyah, Iraq
}

Copyright (C) 2015 by authors, all rights reserved. Authors agree that this article remains permanently open access under the terms of the Creative Commons Attribution License 4.0 International License

\begin{abstract}
In this study two groups of hybrid composite materials were experimentally studied in static uniaxial compression test. The first group consisted of Kevlar/glass fiber and the second group consisted of carbon/glass fiber reinforced epoxy resin. Each group contained four subsets (A, B, C and D) of hybrid composite materials. Compression test was carried out according to ASTM D695 and each test was replicated five times. It was observed that for the same type of hybrid composites, placing carbon or Kevlar fiber layers at the top and bottom; and glass fiber layers in the middle did not give significant effects than placing glass fiber layers at the top and bottom and carbon or Kevlar fiber layers in the middle of the specimens under compressive test. Furthermore, the results showed that hybrid composite laminates for the same number of layers with carbon/glass fiber provided the highest amount of the compressive stress value up to $40 \%$ compared to the results of the group which was reinforced with Kevlar/glass fiber.
\end{abstract}

Keywords Carbon Fibers, Compression Test, Epoxy Resin, Glass Fibers, Hybrid Materials, Kevlar

\section{Introduction}

The use of hybrid composite materials provides more flexibility in several applications because of the materials are merged in such way as to enable us to improve their advantages with the reduction of some of their deficiencies. The constraints compatible to choice and manufacture of traditional materials can be released by using this process of hybridization for tougher and lighter materials, as well as it can offer both cheaper and better solutions for suitable design requirements [1]. Carbon and Kevlar fibers are being used in specialized technology, transportation, preform of a bridge in building and industrial constructions [2]. Hybrid composites normally consist of one high modulus and priced fibers such as carbon fibers, which provide stiffness and load bearing characteristics; while the second is low modulus and low cost like E-glass fibers which provide damage tolerance. Furthermore, stacking configurations and volume fraction of various layers can vary the mechanical characteristic of any hybrid composites materials [3-5].

The capability of a material to withstand axially compressing forces is the compression resistance. A number of researchers have investigated the compression strength of hybrid composite structures, which is one of the significant issues for designers with a number of suggestions that commensurate the trends [6]. Not only the effects of fiber orientation but also the selection of laminate structures on compressive strength of composite laminates was investigated by $\mathrm{Au}$ and Buyukozturk [7] and chosen the best compounds of compressive behaviors. Kuo and others [8] evaluated the responses of three dimensional carbon/carbon composites under axial compressive test. While the influence of different factors, the parameters of the fiber orientation angle and type of loading on the buckling load of square cross ply laminated plates have been examined by Al Qablan and others [9]. Three types of in plane loading were considered; uniaxial compression, shear loading and biaxial compression.

Generally, the use of woven fabric composites in various applications has increased but only limited studies were done on hybridization effect over compressive and tensile loading [10]. Hence, the aim of this work is to experimentally investigate hybrid composites laminated plates which consist of multi layers of woven carbon/E-glass and Kevlar-29/E-glass with epoxy resin under general compression state by using a servo-hydraulic testing machine. A comparison between the test results was evaluated to demonstrate the appropriateness of the hybrid composite material in laminated plate fabrication.

\section{Experimental Procedures}

\section{Materials}

The materials used for the fabrication of the laminated composites were E-glass, carbon and Kevlar mats with epoxy resin (CIBA-GEIGY, CY233) which is a viscous liquid at room temperature and can be turned into a solid state after adding the hardener (HY2992) at a weight ratio 
of 4:1. Table 1 clarifies the mechanical properties, such as Young's modulus, compressive strength and volume density of carbon, glass, Kevlar fibers and epoxy resin that were used.

Table 1. Mechanical properties of the fibers and resin [10].

\begin{tabular}{|c|c|c|c|}
\hline Material & $\begin{array}{c}\text { Modulus of } \\
\text { elasticity }(\mathrm{GPa})\end{array}$ & $\begin{array}{c}\text { Compressive strength } \\
(\mathrm{MPa})\end{array}$ & $\begin{array}{c}\text { Volume dęnsity } \\
(\mathrm{g} / \mathrm{cm})\end{array}$ \\
\hline E-glass & 76 & 1750 & 2.57 \\
\hline Kevlar & 131 & 2750 & 1.44 \\
\hline Carbon & 228 & 3950 & 1.8 \\
\hline Epoxy & 2.8 & 53 & 1.2 \\
\hline
\end{tabular}

Laminated composite fabrication methods

Two sets of hybrid materials were molded by using hand lay-up technique. The first group (Group 1) included Kevlar/glass fiber reinforced epoxy resin and the specimens were labeled as A1, B1, C1 and D1 which contained different layers, as shown in the Table 2. The second group (Group 2) included carbon/glass fibers reinforced epoxy resin and the specimens were labeled as A2, B2, C2 and D2 which contained different layers, as shown in the Table 3.

\section{Preparation of the Specimens}

Glass and Kevlar or carbon fibers were cut to standard size and weighed $\varnothing 20 \mathrm{~mm}$ for specimens A1, A2, B1 and B2; and $\varnothing 17 \mathrm{~mm}$ for specimens $\mathrm{C} 1, \mathrm{C} 2, \mathrm{D} 1$ and D2 because the diameter is specified by thickness which resulted from the number of layers that was used. A plastic mold was utilized in which mold release spray was used, and then a layer of epoxy was coated on the sheet, alternately, layers of Kevlar fabric and glass fabric were laid upon another. Ultimate compressive force and stress were studied experimentally for two groups according to the ASTM D695 specification test [11]. Standard compression specimens were tested and the tests are repeated four times for each group at speed of (2 $\mathrm{mm} / \mathrm{min}$ ).

The glass, Kevlar, carbon and epoxy resin for each group were weighed before molding and the results were presented in Table 4 and Table 5.

Table 2. Number of layers of the fiber plies used in the Group 1 specimens.

\begin{tabular}{|c|c|c|c|c|c|c|c|}
\hline Group 1 & $\begin{array}{c}\text { No. of Kevlar } \\
\text { layers }\end{array}$ & $\begin{array}{c}\text { No. of Kevlar plies } \\
\text { in each layer }\end{array}$ & $\begin{array}{l}\text { Total no. of Kevlar } \\
\text { plies in the specimen }\end{array}$ & $\begin{array}{l}\text { No. of glass } \\
\text { layers }\end{array}$ & $\begin{array}{c}\text { No. of glass plies } \\
\text { in each layer }\end{array}$ & $\begin{array}{c}\text { Total no. of glass } \\
\text { plies in the specimen }\end{array}$ & $\begin{array}{c}\text { Total no. of fibers } \\
\text { plies in the specimen }\end{array}$ \\
\hline $\mathrm{A} 1$ & 3 & 7 & 21 & 2 & 10 & 20 & 41 \\
\hline B1 & 2 & 7 & 14 & 3 & 10 & 30 & 44 \\
\hline $\mathrm{C} 1$ & 1 & 7 & 7 & 2 & 10 & 20 & 27 \\
\hline D1 & 2 & 7 & 14 & 1 & 10 & 10 & 24 \\
\hline
\end{tabular}

Table 3. Number of layers of the fiber plies used in the Group 2 specimens.

\begin{tabular}{|c|c|c|c|c|c|c|c|}
\hline Group 2 & $\begin{array}{c}\text { No. of carbon } \\
\text { layers }\end{array}$ & $\begin{array}{c}\text { No. of carbon plies } \\
\text { in each layer }\end{array}$ & $\begin{array}{c}\text { Total no. of carbon } \\
\text { plies in the specimen }\end{array}$ & $\begin{array}{c}\text { No. of glass } \\
\text { layers }\end{array}$ & $\begin{array}{c}\text { No. of glass plies } \\
\text { in each layer }\end{array}$ & $\begin{array}{c}\text { Total no. of glass plies } \\
\text { in the specimen }\end{array}$ & $\begin{array}{c}\text { Total no. of fibers plies } \\
\text { in the specimen }\end{array}$ \\
\hline A2 & 3 & 7 & 21 & 2 & 10 & 20 & 41 \\
\hline B2 & 2 & 7 & 14 & 3 & 10 & 30 & 44 \\
\hline C2 & 1 & 7 & 7 & 2 & 10 & 20 & 27 \\
\hline D2 & 2 & 7 & 14 & 1 & 10 & 10 & 24 \\
\hline
\end{tabular}

Table 4. Weight of constituents of the test specimens for the Group 1.

\begin{tabular}{|c|c|c|c|c|}
\hline ne & Weight & Glass fiber weight (g) & Kevlar fiber weight (g) & Epoxy weight (g) \\
\hline $\mathrm{A} 1$ & (3 Kevlar layers +2 glass layers) & 5.706 & 2.887 & 6.577 \\
\hline B1 & (2 Kevlar layers +3 glass layers) & 8.493 & 1.869 & 6.578 \\
\hline $\mathrm{C} 1$ & (1 Kevlar layer +2 glass layers) & 5.660 & 0.963 & 4.578 \\
\hline D1 & (2 Kevlar layers + 1 glass layer) & 2.831 & 1.868 & 4.562 \\
\hline
\end{tabular}

Table 5. Weight of constituents of the test specimens for the Group 2.

\begin{tabular}{|c|c|c|c|c|}
\hline & Weight & Glass fiber weight (g) & Carbon fiber weight (g) & Epoxy weight (g) \\
\hline $\mathrm{A} 2$ & ( 3 carbon layers +2 glass layers) & 5.711 & 5.57 & 6.60 \\
\hline $\mathrm{B} 2$ & ( 2 carbon layers +3 glass layers $)$ & 8.492 & 3.67 & 6.463 \\
\hline $\mathrm{C} 2$ & $(1$ carbon layer +2 glass layers $)$ & 5.58 & 1.85 & 4.57 \\
\hline & ( 2 carbon layers +1 glass layer) & 2.81 & 3.70 & 4.65 \\
\hline
\end{tabular}




\section{Results and Discussion}

The compressive test results of yield, maximum compressive force and stress for Group 1 of hybrid composite materials reinforced epoxy resin are shown in the Figs. 1 and 2 respectively. A1 specimens (3Kevlar +2 glass) show highest results of forces with different values of modulus compared with the results of the specimens of B1, C1 and D1 respectively. While the results of the specimens $\mathrm{C} 1$ and D1 had values close to each other at maximum force and stress.

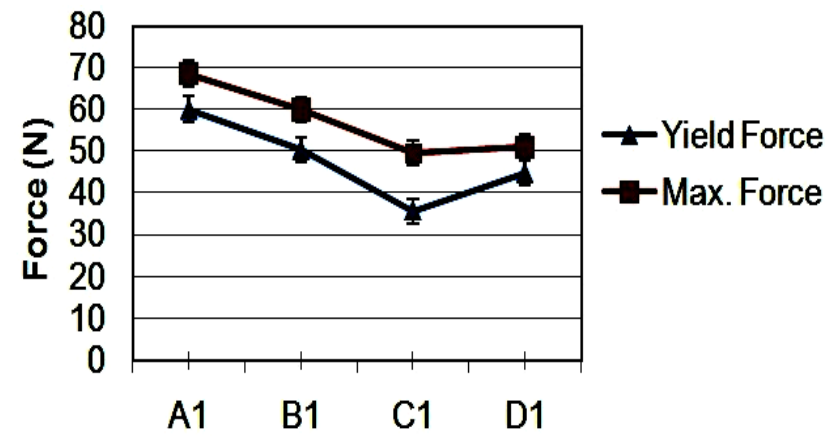

Figure 1. Average results of the yield and maximum force of Group 1 specimens.

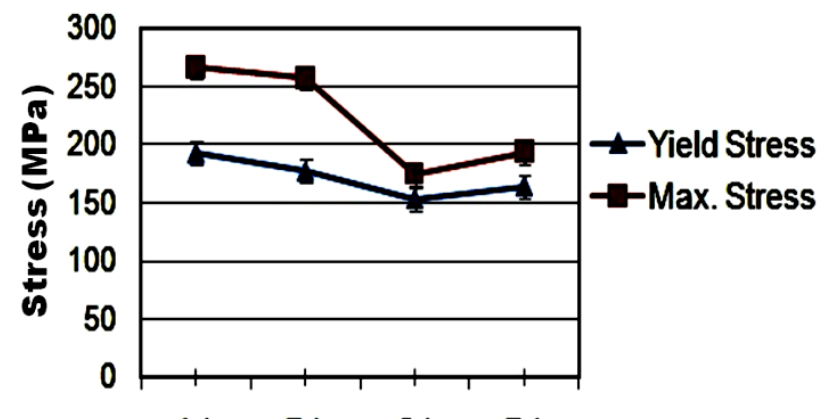

A1 $\quad$ B1 1 C1 $\quad$ D1

Figure 2. Average results of the yield and maximum stress of the Group 1 specimens.

For Group 1, as a result of the high strength of Kevlar fibers over the strength of the glass fibers and an increased in the number of Kevlar layers caused an elevated in the stress pattern of the plastic performance. The maximum rate of the compression stress of the four samples specimens A1 is 266.288 MPa while maximum rate of the compression stress of the specimens B1, C1, D1 were 256.883, 174.49,193.545 $\mathrm{MPa}$ respectively. It is obvious that increasing the number of layers increases the stress capacity by comparing the results of the specimens $\mathrm{A} 1$ and $\mathrm{B} 1$ with the results of the specimens D1 and $\mathrm{C} 1$. While the multi failure behavior of the elongation elastic limits of the samples did not follow a fixed pattern. This is possibly on account of the manual handling in preparing the samples. For the same number of layers, specimens B1 which had 2 layers of Kevlar and 3 layers of glass and specimens A1 with 3 layers of Kevlar and 2 layers of glass, the results showed a remarkable convergence. Furthermore, for the similar number of layers of the hybrid composite material with a greater number of
Kevlar fibers showed the best compression features. In Fig. 3 and 4 , the results of yield and maximum compression force and stress for the Group 2 specimens are shown respectively.

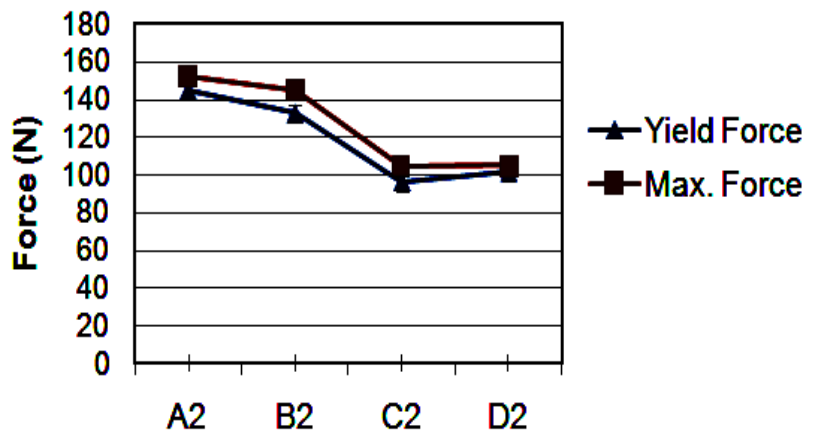

Figure 3. Average results of the yield and maximum force of the Group 2 specimens.

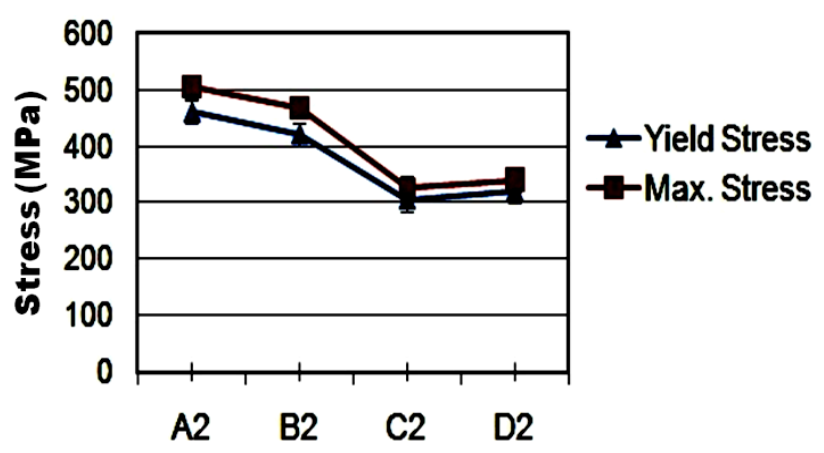

Figure 4. Average results of the yield and maximum stress of the Group 2 specimens.

The laminated composites of carbon layers (Group 2) have superior compressive strength compared with the results of the Group 1 samples. Moreover, the results of the specimens A2, which had a big number of carbon layers, experienced increasing in the stress pattern of the plastic behavior of them. The maximum rate of the compression stress of the four samples of A2 is 506.3

$\mathrm{MPa}$ while the maximum rate of the compression stress of the specimens B2, C2, D2 were 469.79, 327.038, 340.515 $\mathrm{MPa}$ respectively.

The two hybrid composites under the compression test exhibited two distinct behaviors in failure. The first behavior was that the samples fractured at a specific load into two sections. The second failure behavior was that the specimens have been plastically deformed. The compression results of the two groups show that the hybrid composite materials display linear stress-extension relation of certain stresses domain. This is followed by a nonlinear stress-extension relation up to failure. In this difference, hybrid material shows an elastic-plastic behavior [12]. A difference is noticed in the hybrid composites plastic behaviors as compared to metal performance because of an increase in the plastic pattern stress of the hybrid composites up to failure due to the high ductility of plastic materials. This phenomenon is named multi failure [13]. The results of the comparison between Group 1 and Group 2 specimens in the yield and maximum force are shown in the Fig. 5. 

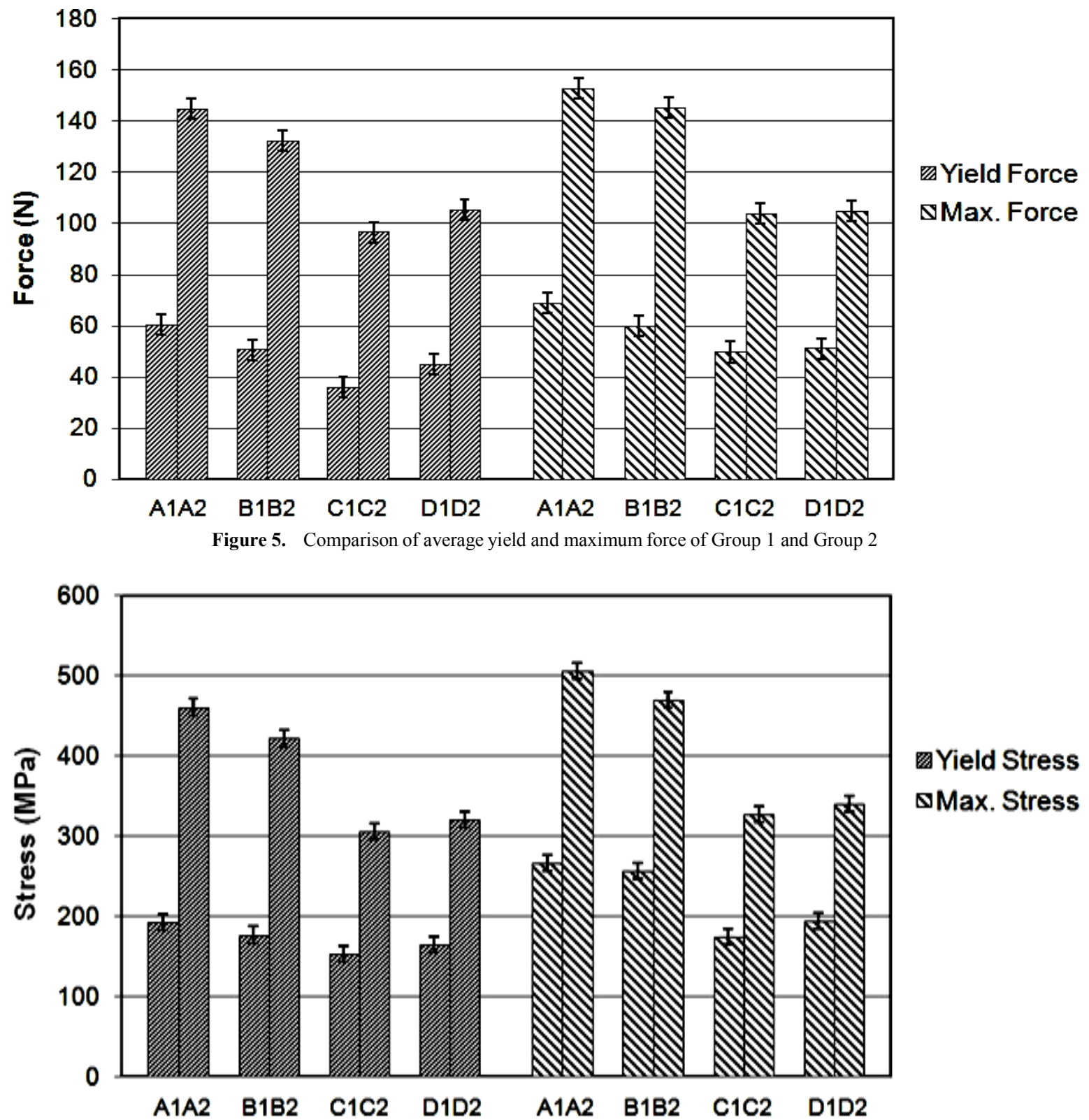

Figure 6. Comparison of average yield and maximum stress of Group 1 and Group 2

The results of the comparison between Group 1 and Group 2 specimens in the yield and maximum stress are shown in the Fig. 6.

\section{Conclusions}

It can be concluded that, the compression strength appeared to obey the rule of number of layers and type of hybrid fiber-reinforced polymer matrix composites. For the same type of hybrid composites, placing carbon or Kevlar in the outer layer and glass layer in the middle has given similar results to placing glass in the outer layer and carbon or Kevlar layer in the middle. Unlike in Group 1, the rate of maximum compression stress increased by increasing the number of glass layers in the Group 2.
Also, at the same number of layers the hybrid composite material that contains carbon/glass fibers was given the best compression characteristics. In the other words, the results showed that for the same number of layers of the hybrid composite laminates which reinforced with carbon/glass fiber provide the highest amount of the compression stress value by up to $40 \%$ compare to composites reinforced with Kevlar/glass fiber. In addition, the results showed that the hybrid composite with one carbon layer and two glass layers was better than the hybrid composite which contains of three Kevlar layers and two glass layers under the compression tests.

\section{Acknowledgements}

The authors would like to express their gratitude and 
sincere appreciation to the Department of Mechanical and Manufacturing Engineering of the Universiti Putra Malaysia and to the Ministry of Higher Education \& Scientific Research of Iraq and to the Material Engineering Department, College of Engineering, University of Mustansiriyah for scientific assistance and support.

\section{REFERENCES}

[1] M. N. Gururaja, A. N. Hari Rao, A Review on Recent Applications and Future Prospectus of Hybrid Composites, International Journal of Soft Computing and Engineering (IJSCE), Vol. 1, Issue 6, pp. 352-355, 2012.

[2] G. Van Erp, Future materials: The Use of Fibre Composites in Civil Engineering, in: Proc. Of Main Roads Technology Forum, Brisbane 2006, Queensland. Australia, 2006.

[3] R. F. Gibson, Principles of Composite Material Mechanics, $3^{\text {rd }}$ ed., CRC Press (C) by Taylor \& Francis Group, 2012.

[4] E. J. Barbero, Introduction to Composite Materials Design, $2^{\text {nd }}$ ed., CRC Press (C) by Taylor \& Francis Group, 2011.

[5] E. Randjbaran, R. Zahari, D. L. Majid, N. A. A. Jalil, R. Vaghei, R. Ahmadi, The Effects of Stacking Sequence Layers of Hybrid Composite Materials in Energy Absorption Under The High Velocity Ballistic Impact Conditions: An Experimental Investigation, Journal of Material Sciences \& Engineering, Vol. 2, Issue 4, pp. 130-137, 2013.

[6] E. Randjbaran, R. Zahari, D. L. Majid, N. A. A. Jalil, R. Vaghei, R. Ahmadi, An Experimental Investigation of the Effects of Stacking Sequence on Laminated Composite Flat
Plates Response to Compressive Load, Current Research in Engineering, Science and Technology, Vol. 1, Issue 9, pp. 163-168, 2013.

[7] C. Au, O. Buyukozturk, Effect of Fiber Orientation and Ply Mix on Fiber Reinforced Polymer-Confined Concrete, Journal of Composites for Construction, Vol. 9, Issue 5, pp. 397-407, 2005.

[8] W. S. Kuo, T. H. Ko, T. S. Lo, Failure Behavior of Three-Axis Woven Carbon/Carbon Composites Under Compressive and Transverse Shear Loads, Composites Science and Technology, Vol. 62, Issue 7-8, pp. 989-999, 2002.

[9] H. Al Qablan, H. Katkhuda, H. Dwairi, Assessment of The Buckling Behavior of Square Composite Plates With Circular Cutout Subjected to in-Plane Shear, Jordan Journal of Civil Engineering, Vol. 3, Issue 2, pp. 184-195, 2009.

[10] E. Randjbaran, R. Zahari, D. L. Majid, N. A. A. Jalil, R. Vaghei, R. Ahmadi, An Experimental Investigation of the Effects of Stacking Sequence on Hybrid Composite Materials Response to Open-Hole Compression Strength, MATRIX Academic International Online Journal of Engineering and Technology, Vol. 1, Issue 2, pp. 1-6, 2013.

[11] ASTM D695-10, Standard Test Method for Compressive Properties of Polymer Matrix Composite Materials, ASTM International, West Conshohocken, PA., 2010.

[12] G. Kretsis, A Review of the Tensile, Compressive, Flexural and Shear Properties of Hybrid Fibre-Reinforced Plastics, Composites, Vol. 18, Issue 1, pp. 13-23, 1987.

[13] S. F. Hwang, C. P. Mao, Failure of Delaminated Interply Hybrid Composite Plates Under Compression, Composites Science and Technology, Vol. 61, Issue 11, pp. 1513-1527, 2001. 